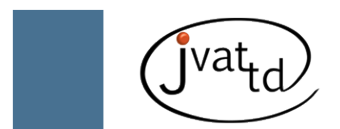

\title{
Study of anticardiolipin antibody in hepatitis C virus-positive patients
}

\author{
Elsayeh H (1), Abdallah N (2), Hamed NA (1), Morsi MG (3), Eldighidy A (4), Kamal HA (5)
}

(1) Department of Internal Medicine, School of Medicine, University of Alexandria, Egypt; (2) Department of Tropical Medicine, School of Medicine, University of Alexandria, Egypt; (3) Department of Medical Microbiology and Immunology, School of Medicine, University of Alexandria, Egypt; (4) Department of Clinical Pathology, School of Medicine, University of Alexandria, Egypt; (5) Department of Medical Biochemistry, School of Medicine, University of Alexandria, Egypt.

\begin{abstract}
Several antibodies, including anticardiolipin antibodies (ACA), have been detected among chronically infected hepatitis $C$ virus (HCV) patients. The present work aimed at ascertaining the clinical significance of ACA levels among HCV infection associated with two commonly encountered diseases, thrombocytopenia and arteriovenous-shunt malfunction. Six groups were studied, $11 \mathrm{HCV}$-positive thrombocytopenic patients (group I), $14 \mathrm{HCV}$-positive non-thrombocytopenic patients (group II) and 15 healthy controls (group III), 11 anti-HCV-positive hemodialysis patients with non-functioning shunt (group IV), 14 anti-HCV-positive hemodialysis patients with patent shunt (group V) (Bain Medical Equipment Co., China) and 15 healthy controls (group VI). Anticardiolipin antibody (ACA) assay was performed on all patients and controls whereas tumor necrosis factor a (TNF- $a$ ) assay was carried out on thrombocytopenic patients and controls. Thrombocytopenic groups presented an inverse correlation between IgG ACA levels and both thrombocytopenia and TNF-a levels. During the follow-up period, no other clinical manifestations related to ACA were developed. Hemodialysis groups showed a significant elevation in IgG ACA levels in groups IV and V compared to the controls, with statistically higher levels in group IV than group V. Three group IV patients were hypercholesterolemic. We can conclude that induction of proinflammatory cytokines such as TNF-a by persistent HCV infection may promote the generation of ACA. Complications of HCV, including thrombocytopenia and thrombosis in arteriovenous shunt, are more strongly correlated with IgG ACA than with IgM ACA.
\end{abstract}

Key words: hepatitis C virus, hemodialysis, anticardiolipin antibody, enzyme-linked immunosorbent assay.

\section{INTRODUCTION}

It has been reported that $\mathrm{HCV}$ prevalence in Egypt is $14.7 \%$ which is ten times greater than the worldwide figure. Prevalence of HCV in Western countries is less than $2 \%(1)$. HCV infection may lead to autoimmune response. It has been reported that chronically infected $\mathrm{HCV}$ patients possess anti-smooth muscle antibodies, rheumatoid factor, anti-liver-kidney-microsomal antibodies, anticardiolipin antibodies (ACA), and low titers of antinuclear antibodies (2). Interferon treatment of $\mathrm{HCV}$ infection may precipitate or exacerbate the associated autoimmune disease (3).
The presence of ACA in viral or other infections may be induced by disturbances in the regulation of cellular and humoral immunity, as a consequence of infectious diseases. Moreover, the stimulation of apoptosis by the viruses may lead to redistribution of plasma membrane phospholipids and their overexpression on the apoptotic cell membrane surfaces resulting in the formation of ACL antibodies. In patients with chronic viral hepatitis, induction of neoantigens may provoke antibody formation by rupturing the liver cell membrane (4).

$\mathrm{HCV}$ is increasingly recognized as a significant cause of extrahepatic manifestations, 
such as Sjögren's syndrome, de novo or recurrent membranoproliferative glomerulonephritis, leukocytoclasticvasculitis and acute transplant glomerulopathy in transplanted kidneys (4). A few reports have suggested an association between ACA and renal allograft thrombosis (5). Recently, several conflicting results have been reported in relation to raised IgG and IgM ACA titers in hemodialysis (HD) patients and their role in vascular access dysfunction (6).

Therefore, the present study aimed to assess the clinical significance of ACA levels among diseases commonly associated with HCV, namely thrombocytopenia and arteriovenous shunt malfunction.

\section{SUBJECTS AND METHODS}

Levels of ACA antibodies were determined among six groups (50 patients and 30 controls). All cases were positive for anti-HCV antibodies by ELISA Murex anti-HCV (version 3, USA) and positive for HCV RNA through a reverse transcriptase PCR by the Trizol method (RNA Isolation $^{\circ}$, Life Technologies, USA). Group I consisted of $11 \mathrm{HCV}$-positive thrombocytopenic patients, group II comprised $14 \mathrm{HCV}$-positive non-thrombocytopenic patients. The results were compared with 15 healthy controls, of matched age and sex, negative for HBsAg, anti-HCV and HIV (group III). Patients were randomly selected and followed up regularly every three months for one year for the development of other manifestations of antiphospholipid antibody syndrome. Seven patients with HCV had been treated with $\alpha$ interferon (IFN- $\alpha$ ); however, all of them had stopped receiving the treatment at least six months before the experimental phase. The study also included two anti-HCV antibodypositive groups on chronic hemodialysis, 11 with malfunctioning of the shunt (group IV) and 14 with patent shunt (group V). In group IV, three patients were hypercholesterolemic. Results were compared with 15 healthy controls negative for HBsAg, anti-HCV and HIV of matched age and sex (group VI).

All patients were subjected to: thorough history taking and clinical examination with special stress on other clinical manifestation of APS, and previous clinical findings of thrombosis detected clinically or by echocardiography. Complete blood profile including platelet count, liver function tests, platelet specific antibody by modified antigen capture ELISA (only in thrombocytopemic patients), Anticardiolipin antibody assay were done using ELISA (Demeditec Diagnostics, Germany). The ACA concentration was measured in international units (with one unit being equivalent to the binding activity of one $\mathrm{mg}$ of $\mathrm{aCL} / \mathrm{mL}$ ). Samples were considered positive when the value was higher than $10 \mathrm{GPL}$ or $10 \mathrm{MPL}$; quantitative measurement of serum tumor necrosis factor a (TNF- $\alpha$ ) using the RayBio ${ }^{\circ}$ ELISA kit (UK), was performed only on thrombocytopenic patients. Patients who had previous exposure to HBV, HIV or any autoimmune disease were excluded from the study. None of our subjects was diabetic or had a history of alcohol abuse or recent Interferon treatment. Interferon had been stopped at least 6 months before the study among those under treatment.

\section{Statistical Analysis}

The SPSS package, version 9.0 for Windows ${ }^{\circ}$ (Microsoft, USA), was used for statistical analysis of data. Chi-square test was used to ascertain differences between group I and group II in relation to previous interferon therapy. ANOVA test was used to compare the studied parameters in the HCV-infected individuals versus controls. Pearson's correlation was used to study the correlation between ACA and the various studied parameters. Probability values of less than 0.05 were considered statistically significant.

\section{RESULTS}

Clinical and the laboratory data of groups I and II (11 women and 14 men; between 17 and 52 years old) are shown in Tables 1 and 2, respectively. In group I, thrombocytopenia was moderate in eight patients, mild in two patients and severe in only one patient (whose platelet count was $37 \times 10^{9} / \mathrm{L}$ ). No bleeding was manifested by any studied patient. Table 3 shows a correlation among platelet counts, IgG ACA and TNF- $\alpha$. There was a direct correlation between TNF- $\alpha$ and IgG ACA $(r=0.674, p=0.023)$.

Clinical and laboratory data of hemodialysis patients, shown in Tables 4 and 5, reveal significantly higher IgG ACA values among subjects of groups IV and V than those VI with statistically higher levels in group IV than V. The 
Table 1. Clinical data of thrombocytopenic patients

\begin{tabular}{c|c|c|c|c}
\hline Parameter & Group I $(\mathbf{n}=11)$ & Group II $(\mathbf{n}=14)$ & Group III $(\mathbf{n}=15)$ & p value \\
\hline Age (years) & $33.27 \pm 9.91$ & $28.07 \pm 7.898$ & $28.6 \pm 5.75$ & 0.215 \\
\hline Previous interferon therapy & 3 & 4 & - & 0.943 \\
\hline
\end{tabular}

Table 2. Laboratory data of thrombocytopenic patients

\begin{tabular}{c|c|c|c|c}
\hline Parameter & Group I & Group II & Group III & p value \\
\hline ALT (U/L) & $57.82 \pm 14.29^{*}$ & $53.07 \pm 5.37$ & $16.93 \pm 1.87^{* * *}$ & $<0.01$ \\
\hline Platelet count (x 10\%/L) & $60.45 \pm 14.16^{*}$ & $165.07 \pm 12.84^{* *}$ & $337.07 \pm 48.21^{* * *}$ & $<0.01$ \\
\hline IgG ACA (GPL units/mL) & $19.45 \pm 2.91^{*}$ & $16.43 \pm 2.38^{* *}$ & $8.33 \pm 1.05^{* * *}$ & $<0.01$ \\
\hline IgM ACA (MPL units/mL) & $12.27 \pm 1.74^{*}$ & $10.43 \pm 1.02^{* *}$ & $6.07 \pm 0.88^{* * *}$ & $<0.01$ \\
\hline TNF-a (pg/mL) & $61.64 \pm 18.33^{*}$ & $47.43 \pm 10.62^{* *}$ & $32.89 \pm 3.66^{* * *}$ & $<0.01$ \\
\hline
\end{tabular}

$\mathrm{p}$ is significant if $\leq 0.05 ;{ }^{*}$ : groups I and III are significant; **: groups II and III are significant; ***: groups I and II are significant.

Table 3. Correlation between platelet counts, TNF- $a$ and ACA values among thrombocytopenic patients

\begin{tabular}{c|c|c|c|c}
\hline Parameter & p value & $\begin{array}{c}\text { IgG ACA } \\
\text { (GPL units } / \mathrm{mL})\end{array}$ & $\begin{array}{c}\text { IgM ACA } \\
\text { (MPL units } / \mathrm{mL})\end{array}$ & $\begin{array}{c}\text { TNF-a } \\
(\mathrm{pg} / \mathrm{mL})\end{array}$ \\
\hline \multirow{2}{*}{ Platelet counts in group I } & $\mathrm{r}$ & $-0.612^{*}$ & 0.084 & $-0.716^{*}$ \\
& $\mathrm{p}$ & 0.045 & 0.806 & 0.013 \\
\hline \multirow{2}{*}{ Platelet counts in group II } & $\mathrm{r}$ & -0.316 & -0.132 & -0.179 \\
& $\mathrm{p}$ & 0.217 & 0.652 & 0.45 \\
\hline
\end{tabular}

$p$ is significant if $\leq 0.05$.

Table 4. Clinical data of hemodialysis patients

\begin{tabular}{c|c|c|c|c}
\hline Parameter & Group IV $(\mathbf{n}=\mathbf{1 1})$ & Group V $(\mathbf{n}=14)$ & Group VI $(\mathbf{n}=15)$ & p value \\
\hline Age (years) & $30.73 \pm 8$ & $28.79 \pm 7.86$ & $29 \pm 5.46$ & 0.766 \\
\hline
\end{tabular}

$p$ is significant if $\leq 0.05$. 
Table 5. Laboratory data of hemodialysis patients

\begin{tabular}{c|c|c|c|c}
\hline Parameter & Group IV $(\mathbf{n}=11)$ & Group V $(\mathbf{n}=14)$ & Group VI $(\mathbf{n}=15)$ & p value \\
\hline ALT (U/L) & $60.09 \pm 12.44^{*}$ & $54.21 \pm 5.19$ & $16.93 \pm 1.87^{* *}$ & 0.01 \\
\hline IgG ACA (GPL units/mL) & $19 \pm 2.68^{*}$ & $15.71 \pm 1.64^{* * *}$ & $8.33 \pm 1.55^{* *}$ & $<0.01$ \\
\hline IgM ACA (MPL units/mL) & $8.36 \pm 1.12^{*}$ & $10.43 \pm 1.02$ & $6.07 \pm 0.88^{* *}$ & $<0.01$ \\
\hline
\end{tabular}

$p$ is significant if $\leq 0.05$; *: groups IV and VI are significant; **: groups $V$ and $V I$ are significant; ***: groups IV and $V$ are significant.

Table 6. Correlation between ALT level and ACA values

\begin{tabular}{c|c|c|c}
\hline Parameter & p value & IgG ACA (GPL units $/ \mathrm{mL})$ & IgM ACA (MPL units $/ \mathrm{mL})$ \\
\hline \multirow{2}{*}{ ALT in group IV } & $\mathrm{r}$ & -0.336 & -0.139 \\
& $\mathrm{p}$ & 0.313 & 0.684 \\
\hline \multirow{2}{*}{ ALT in group V } & $\mathrm{r}$ & -0.503 & 0.187 \\
& $\mathrm{p}$ & 0.067 & 0.522 \\
\hline
\end{tabular}

$p$ is significant if $\leq 0.05$.

IgMlevel was significantly higher in groups IV and $\mathrm{V}$ than VI without significant difference in IgM ACA levels between groups IV and V. In group IV, three patients were hypercholesterolemic.

Table 6 shows the correlation among ALT, IgG and IgM ACA among groups IV and V. The studied groups did not differ as to the clinical course of HCV. During the follow-up period, none of our patients showed any other of the following clinical manifestations related to those autoantibodies: recurrent abortions, thrombosis, hemolysis, vasculitis or livedoreticularis.

\section{DISCUSSION}

The clinical features typical of antiphospholipid syndrome (APS) are less commonly observed with aPL associated with infections. Some infections, however, have been more likely to be associated with the subsequent development of thrombosis (leprosy, parvovirus B19, HIV, HCV, CMV). Infection may be the triggering factor in as many as $40 \%$ of cases of catastrophic antiphospholipid syndrome (CAPS) (7). Thrombocytopenia is one of the clinical manifestations of ACA syndrome. Among group I (HCV-positive thrombocytopenic patients), thrombocytopenia was moderate in severity in the majority of patients (platelet count between $50,000 / \mu \mathrm{L}$ and $75,000 / \mu \mathrm{L})(8)$. Delayed diagnosis of such cases may result from the absence of a bleeding manifestation. In our cases, thrombocytopenia is inversely correlated with IgG ACA levels among group I while IgM ACA levels did not correlate with the degree of thrombocytopenia. The discrepancy of results between different studies is more common with samples from patients with low levels of ACA (9).

Another variable that can alter the ACA assay results is considering or ignoring non-specific binding of antibodies in the ELISA plate that is, binding of antibody on a well that has not been coated with the antigen. This phenomenon is seen more frequently with the IgM and IgA isotypes (10). There was a direct correlation between TNF- $\alpha$ and IgG ACA levels among group I. Persistent HCV infection leads to endothelial and hepatic damage that can cause alteration of the expression of cell surface phospholipids and induction of proinflammatory cytokines, which together may promote the generation of ACA (11). As to the arteriovenous shunt malfunction, our results revealed the presence of statistically significant elevation in IgG ACA levels among groups IV and V compared to controls with significantly higher levels among group IV than group V. Vascular access thrombosis (VAT) is a 
major cause of morbidity in chronic hemodialysis (HD) patients. IgG ACA is strongly associated with venous and arterial thrombosis in patients with normal renal function (12).

A study done by Ozmen et al. (13) on 103 hemodialysis patients revealed a $14.6 \%$ prevalence of IgG ACA (15/103). No patient presented a positive value on the IgM ACA test. $\mathrm{HCV}$ was detected in 52 of 76 patients. With regard to the remaining parameters, subjects with and without ACA IgG did not differ significantly. No difference in arteriovenous fistula survival was detected between ACA (+ve) and ACA (-ve) groups (13).

Another study by Lee et al. (14) that enrolled 98 chronic $\mathrm{HCV}$ patients undergoing $\mathrm{HD}$ revealed contrasting results. The IgG ACA titers were elevated in $29.6 \%(29 / 98)$ of patients. The IgG ACA level did not differ according to shunt type between the two groups. There was a strong association between an augmented IgG ACA titer and recurrent vascular access thrombosis (VAT). The prevalence of raised IgG ACA titers was 39.6\% among chronic HCV with HD patients. Furthermore, a raised IgG ACA titer and recurrent VAT were also closely associated. In our study, three members of group I were hypercholesterolemic, which may signify an additional role for a risk factor like hypercholesterolemia in association with elevated IgG ACA in VAT malfunctioning. The IgM ACA levels were statistically higher among groups IV and $\mathrm{V}$ compared to controls with no significant difference between groups IV and V.

An elevated IgM ACA titer was associated with vascular access stenosis in HD patients. The clinical significance of elevated IgM ACA titer relative to recurrent VAT in patients with HD is less clear (15). No differences in the clinical course of HCV between the studied groups were found. In addition, none of our patients with $\mathrm{HCV}$ or ACA showed any other clinical manifestations related to those autoantibodies namely, recurrent abortions, thrombosis, hemolysis, vasculitis or livedo reticularis. Most of the published data agree that ACA were frequently found in patients with chronic HCV infection, but they did not appear to be of clinical importance.

Some studies, however, have found an increased incidence of thrombotic disorders in patients with chronic HCV who manifest antiphospholipid positivity. More prospective, long-term studies are required in order to address whether $\mathrm{HCV}$ is involved or not in the etiopathogenesis of antiphospholipid syndrome (16).

The present work revealed no correlation between ALT and either IgG ACA or IgM ACA levels. Serum ALT levels were elevated among 24- $67 \%$ of dialysis patients who were anti-HCVpositive. Elevated serum transaminases were present among $31 \%$ of the HCV RNA-positive hemodialyzed patients and $30 \%$ of those who had biopsy-proven hepatitis (17).

\section{CONCLUSION}

$\mathrm{HCV}$ associated diseases such as thrombocytopenia and arteriovenous-shunt thrombosis are more closely related to IgG ACA than IgM ACA. Absence of bleeding manifestation may be responsible for delay in diagnosis of these cases. Induction of high TNF- $\alpha$ by persistent $\mathrm{HCV}$ infection may promote the generation of ACA. Further studies with larger patient sample size are still recommended to confirm our findings.

\section{ACKNOWLEDGEMENTS}

We would like to thank all those who helped us accomplish this work and publish it.

\section{COPYRIGHT}

(C) CEVAP 2011

\section{SUBMISSION STATUS}

Received: April 26, 2011.

Accepted: August 12, 2011.

Abstract published online: August 16, 2011.

Full paper published online: November 30, 2011.

\section{CONFLICTS OF INTEREST}

There is no conflict.

\section{FINANCIAL SOURCE}

Faculty of Medicine, Alexandria University, provided the infrastructure including laboratory equipments and paramedical personal. The authors purchased the chemical reagents.

\section{ETHICS COMMITTEE APPROVAL}

The present study followed the Ethical Guidelines for Conduct of Research on Human Subjects and was approved by the Ethics Committee of Alexandria University, Egypt. 


\section{CORRESPONDENCE TO}

MONA GAMAL MORSI, Department of Medical Microbiology and Immunology, School of Medicine, Alexandria University, Sultan Hussein, Al Azarita, Alexandria, Egypt. Phone: 01005171621. Email: morsirg@yahoo.com.

\section{REFERENCES}

1. El-Zanaty F, Way A. Egypt Demographic and Health Survey 2008. Cairo, Egypt: Ministry of Health; 2009. $431 \mathrm{p}$.

2. Ordi-Ros J, Villarreal J, Monegal F, Sauleda S, Esteban I, Vilardell M. Anticardiolipin antibodies in patients with chronic hepatitis $\mathrm{C}$ virus infection: characterization in relation to antiphospholipid syndrome. Clin Diagn Lab Immunol. 2000;7(2):241-4.

3. Mouelhi L, Debbeche R, Sfar I, Salem M, Bouzaidi S, Trabelsi S, et al. Auto-immune serological disorders in chronic viral C hepatitis: prevalence and clinical significance. Tunis Med. 2008;86(9):777-81.

4. Sthoeger ZM, Fogel M, Smirov A, Ergas D, Lurie Y, Bass DD, et al. Anticardiolipin autoantibodies in serum samples and cryoglobulins of patients with chronic hepatitis $\mathrm{C}$ infection. Ann Rheum Dis. 2000;59(6):483-6.

5. Knight RJ, Schanzer H, Rand JH, Burrows L. Renal allograft thrombosis associated with the antiphospholipid antibody syndrome. Transplantation. 1995;60(6):614-5.

6. Chuang FR, Chang HW, Lin CL, Wang IK, Chang $\mathrm{HY}$, Wang $\mathrm{PH}$, et al. Anticardiolipin antibody and Taiwanese chronic haemodialysis patients with recurrent vascular access thrombosis. Int J Clin Pract. 2005;59(7):785-90.

7. Sène D, Piette JC, Cacoub P. Antiphospholipid antibodies, antiphospholipid syndrome and infections. Autoimmun Rev. 2008;7(4):272-7.

8. Afdhal N, McHutchison J, Brown R, Jacobson I, Manns M, Poordad F. Thrombocytopenia associated with chronic liver disease. J Hepatol. 2008;48(6):10007.
9. Habibagahi Z, Nazarinia MA, Aflaki E, Rajaee Akbar. Anticardiolipin and antibeta2glycoprotein 1 antibodies in patients with hepatitis B and C infections. Iran J Immunol. 2007;4(3):160-5.

10. Kisiel E, Kryczka W. Antiphospholipid antibodies with HCV infection. Innocent proteins or risk factor? Przegl Lek. 2007;64(7-8):521-4.

11. Selva-O'Callaghan A, Ordi-Ros J, Monegal-Ferran F, Martinez N, Cortes-Hernandez F, Vilardell-Tarres M. IgA anticardiolipin antibodies: relation with other antiphospholipid antibodies and clinical significance. Thromb Haemost. 1998;79(2):282-5.

12. Chuang FR, Chang HW, Lin CL, Wang IK, Chang $\mathrm{HY}$, Wang $\mathrm{PH}$, et al. Anticardiolipin antibody and Taiwanese chronic haemodialysis patients with recurrent vascular access thrombosis. Int J Clin Pract. 2005;59(7):785-90.

13. Ozmen S, Danis R, Akin D, Batun S. Anticardiolipin antibodies in hemodialysis patients with hepatitis $\mathrm{C}$ and their role in fistula failure. Clin Nephrol. 2009;72(3):193-8.

14. Lee CH, Wang IK, Chen TC, Chang HW, Yang CC, Chien YS, et al. Anticardiolipin antibodies and vascular access thrombosis in Taiwanese haemodialysis patients with chronic hepatitis C: a retrospective study. Int J Clin Pract. 2006;60(12):1591-5.

15. Chuang FR, Chen TC, Yang CC, Cheng YF, Hsu $\mathrm{KT}$, Lee $\mathrm{CH}$, et al. IgM-anticardiolipin antibody and vascular access thrombosis in chronic hemodialysis patients. Ren Fail. 2005;27(1):25-30.

16. Dalekos GN, Kistis KG, Boumba DS, Voulgari P, Zervou EK, Drosos AA, et al. Increased incidence of anti-cardiolipin antibodies in patients with hepatitis $\mathrm{C}$ is not associated with aetiopathogenetic link to antiphospholipid syndrome. Eur J Gastroenterol Hepatol. 2000;12(1):67-74.

17. Pereira BJ, Levey AS. Hepatitis C virus infection in dialysis and renal transplantation. Kidney lnt. 1997;51(4):981-99. 